\title{
INCIDENCE OF PLASMID MEDIATED ANTIBIOTIC \\ RESISTANCE AMONG ISOLATES FROM TOOTH \\ INFECTIONS IN A DEVELOPING COUNTRY, (SRI LANKA)
}

\author{
T. VINAYAGAMOORTHY \\ Microbiology Unit, Department of Botany, University of Jaffna, \\ Jaffna, Sri Lanka. \\ (Date of receipt : 11 February 1985) \\ (Date of acceptance : 17 February 1986)
}

\begin{abstract}
Out of 55 isolates from tooth infections, the majority were enteric strains. Further, more than $90 \%$ of them exhibited multiple drug resistance. However, the incidence of strains carrying transferable resistance was very low $(<2 \%)$. Therefore, it is inferred that the source of these causal organisms could be the contaminated water which exhibited a similar pattern of antibiotic resistance and transferability. Such incidence of strains in the buccal cavity could facilitate the spread of resistance to other sensitive strains of the nasopharynx.
\end{abstract}

\section{Introduction}

Tooth infections are mainly caused by gram positive nasopharyngeal flora e.g. Staphylococcus aureus, Streptococcus pyogens. ${ }^{6}$ In addition, it was reported ${ }^{7}$ that gram negative bacilli such as Klebsiella, Proteus and Escherichia coli could bring about tooth infections. These organisms enter the mouth via contaminated food and water. Studies carried out ${ }^{5}$ show that the carrier rate of Klebsiella in the throat of a "normal population" is high. Enteric strains isolated from clinical samples, water sources and from rectal swabs of normal healthy adults from this area exhibited a high incidence of multiple resistance and significant percentages of transferable resistance to most of the common antibiotics. ${ }^{9}$ The presence of such enteric strains in the nasopharyngeal region could render a greater chance for the rest of the sensitive "normal flora" to acquire resistance. This study was carried out to assess the incidence of plasmid mediated antibiotic resistance among enteric strains isolated from tooth infections.

\section{Materials and Methods}

\subsection{Collection of Samples}

Tooth swabs were collected from patients suffering from tooth infections. These swabs were collected from patients visiting private dental clinics and 
the dental clinic attached to the General Hospital, Jaffna. The samples were collected by the dental surgeon in sterile peptone water using sterile swabs. These swabs were incubated in peptone water at $37^{\circ} \mathrm{C}$ for $5 \mathrm{~h}$. Subsequently, they were streaked on MacConkey agar medium and incubated for $15 \mathrm{~h}$ at $37^{\circ} \mathrm{C}$. Colonies appearing on these plates were subcultured and identified. ${ }^{2}$

\subsection{Antibiotic Sensitivity Test}

Isosensitest agar medium (oxoid) was used as the test medium. Bacterial resistance to antibiotics were determined by the paper disc method. ${ }^{3}$ A single colony of the pure culture was suspended in $4.5 \mathrm{ml}$ of $0.9 \%$ sterile saline. This was diluted $1: 10$ in the same diluent (adjusted to) standard turbidity and streaked evenly on the test medium using sterile absorbent cotton wool swabs. The plates were incubated at $37^{\circ} \mathrm{C}$ for $15 \mathrm{~min}$. This was followed by the application of antibiotic discs on the inoculated surface and the plates were left at room temperature $\left(28^{\circ} \mathrm{C}\right)$ for $15 \mathrm{~min}$. They were then incubated for $15 \mathrm{~h}$ at $37^{\circ} \mathrm{C}$. The diameter of the zone of inhibition was measured using a vernier caliper. Selection plates were prepared by incorporating sulphamethoxazole $(500 \mu \mathrm{g} / \mathrm{ml})$ nalidixic acid $(30 \mu \mathrm{g} / \mathrm{ml})$ in isosensitive test agar medium. The list of antibiotics used are given in Table 1.

Table 1 : List of Antibiotics used.

Antibiotics
Amount of antibiotic

per disc
1. Nalidixic acid

2. Ampicillin

3. Chloramphenicol

4. Tetracycline

5. Nitrofurantoin

6. Sulphamethoxazole

7. Trimethoprim

8. Erythromycin

9. Gentamicin
(NA)

$(\mathrm{Cm})$

(Em)

$(\mathrm{Gm})$
$30 \mu \mathrm{g}$

$10 \mu \mathrm{g}$

$30 \mu \mathrm{g}$

$30 \mu \mathrm{g}$

$30 \mu \mathrm{g}$

$23.2 \mu \mathrm{g}$

$1.3 \mu \mathrm{g}$

$15 \mu \mathrm{g}$

$30 \mu \mathrm{g}$ 


\subsection{R-Plasmid Transfer by Conjugation}

E. coli K12 strain EC 1005 (met $^{-}$, nal ${ }^{\mathrm{r}}$ ) was used as the reciprent strain. This strain was supplied by Institute of Pharmaceutical Microbiology University of Uppsala, Sweden, (E. coli K12 met $^{-}$rif $^{\mathrm{r}}$ ) was used as the recipient when conjugation with nalidixic acid resistant donors was carried out. A single colony of the recipient was suspended in $50 \mathrm{ml}$ of Luria broth in $150 \mathrm{ml}$ Erlmeyer flask. The broth was diluted to O.D. (optical density) of 0.23 at $600 \mathrm{~nm}$ in the same broth and incubated to O.D. 0.42 at the same wavelength. $0.4 \mathrm{ml}$ of this broth was mixed with the presumptive donor (in $0.2 \mathrm{ml}$ of Luria broth) which was previously incubated for $1 \mathrm{~h}$. The mix ture was incubated at $37^{\circ} \mathrm{C}$ for $15 \mathrm{~h}$ and transferred by a sterile multiple incubator on to selection plates. The selection plates were incubated for $48 \mathrm{~h}$ and colonies appearing on these plates were restreaked to individual colonies on the same selection plates and subsequently tested for recipient auxotrophic marker by culturing them on methionine supplemented minimal salt medium M9. An antibiotic sensitivity test was carried out on these transconjugants and transferable antibiotic resistance patterns were discerned.

\section{Results}

A total of 55 aerobic gram negative bacterial strains was isolated from 53 tooth infections. The majority of the isolates (49\%) were Klebsiella (Table 2). The 55 isolates were found to exhibit resistance to more than one antibiotic. The majority of the isolates were resistant to ampicillin , sulphamethoxazole and trimethoprim. Further, significant amounts (58\%) of the isolates were resistant to nitrofurantoin. Though none of the isolates were resistant to gentamicir, a few were resistant to tetracycline and chloramphenicol. Thirty-four different resistance patterns were observed among strains isolated from tooth infections (Table 3). Resistance patterns were observed carrying resistance markers up to 8. Out of the different resistance patterns exhibited by Klebsiella, resistance to ampicillin , sulphamethoxazole, nitrofurantoin and trimethoprim was predominant (37\%). All isolates of $E$. coli carried resistance to ampicillin, sulphamethoxazole and trimethoprim. This particular combination of resistance genes was also observed among Paracolon, Proteus and Klebsiella. All isolates exhibiting antibiotic resistance were conjugated with $E$. coli $\mathrm{K} 12$ EC1005 (met $^{-}, \mathrm{nal}^{\mathrm{r}}$ ) and selected with nalidixic acid $(50 \mu \mathrm{g} / \mathrm{ml})$ and sulphame thaxazole $(500 \mu \mathrm{g} / \mathrm{ml})$. A Proteus strain carrying resistance to ampicillin , tetracycline, sulphamethoxazole, erythromycin, chloramphenicol, nitrofurantoin and trimethoprim was found to transfer resistance to sulphamethoxazole: 


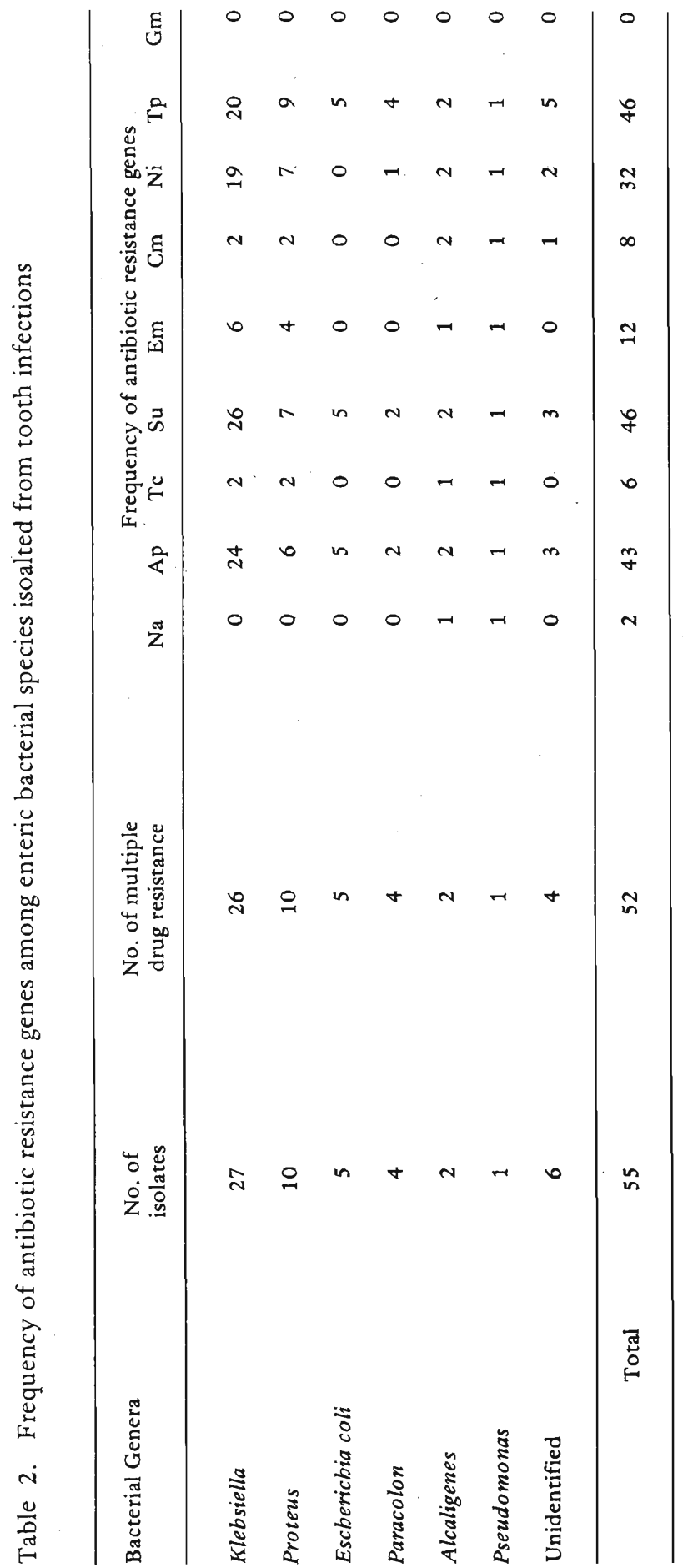


Table 3. Frequency of antibiotic resistance patterns among enteric bacteria isolated from tooth infections

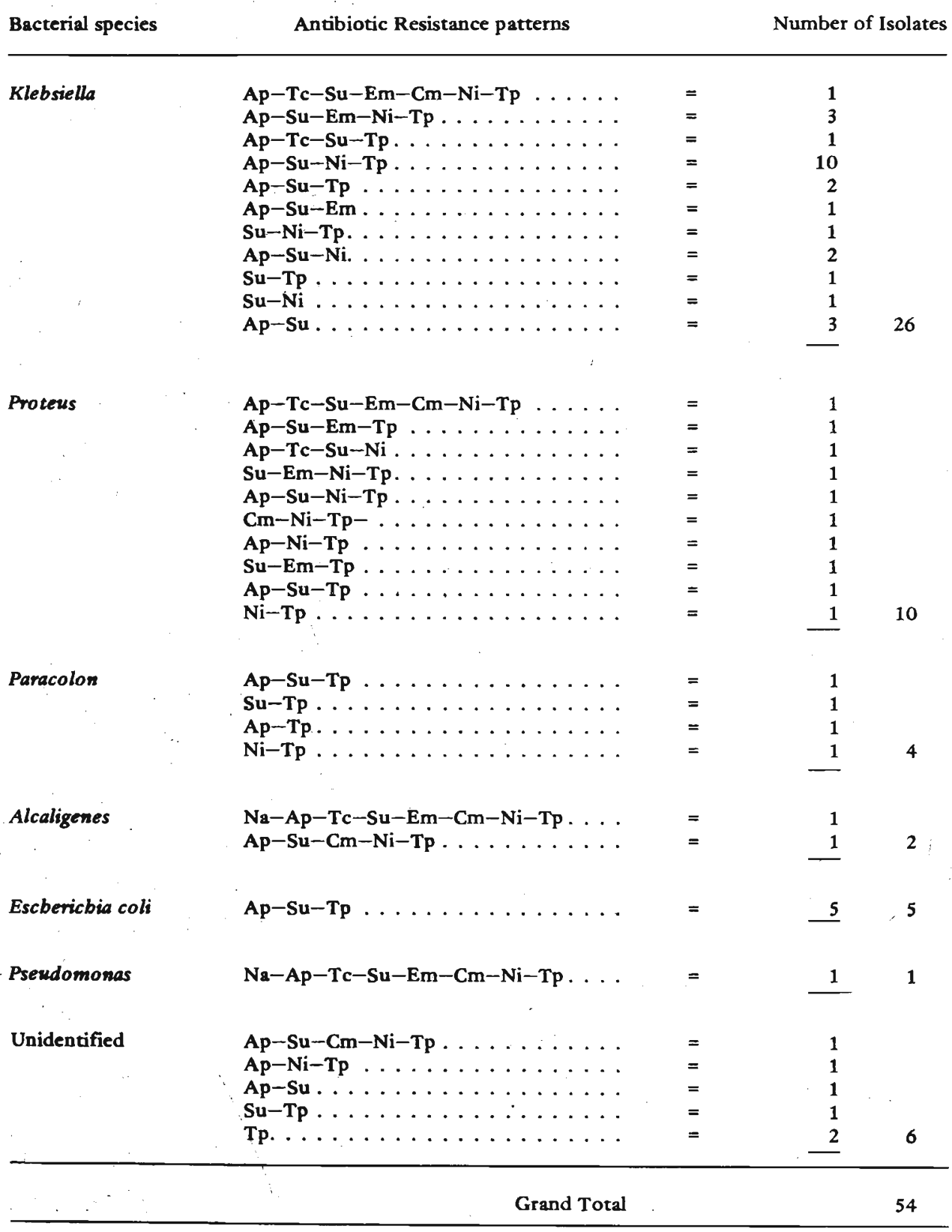




\section{Discussion}

Incidence of multiple drug resistance strains among tooth infections suggest that these organisms could have originated from antibiotic loaded environments. Such environments could be either the clinical source, human or animal intestinal flora. Further, these isolates share common resistance patterns with that of the corresponding strains isolated from water sources. ${ }^{8}$ Earlier studies 9 showed that the resistant enteric strains isolated from water sources did not transfer their resistant traits to sensitive strains. Nontransferability of these resistant genes could be due to the loss of transfer genes responsible while they are in a non-selective medium such as water. A similar phenomenon was observed among the isolates from tooth infections where inspite of the high incidence of resistant isolates only one out of 55 isolates transferred these resistance genes to sensitive strains. This further shows that tooth infections could also be caused by resistant enteric strains of human origin and could spread in the community via contaminated water.

Recently it has been reported that R-plasmid transfer by conjugation could occur between Staphylococcus and E. coli. ${ }^{1}$ The presence of a high incidence of resistant strains in the nasopharyngeal region could increase the chances of other sensitive normal flora such as Neisseria. Staphylococcus, Streptococcus acquiring such resistance. The non-parental use of antibiotics during tooth extraction 'as a prophylactic agent could remove the normal sensitive organisms from the nasopharynx and their place could be occupied by resistant enteric strains, thus bringing about chronic soreness. Stabilization of strains like Klebsiella flexeneri in the nasopharynx could render the chance of the individual suffering from pneumonia caused by the same organism.

Thus steps should be taken to prevent the access of enteric strains to the mouth and nasopharynx. This could be achieved by the use of treated water and maintaining high standards of personal hygiene. Further the use of antibiotics in the community should be reduced so that the incidence of resistant strains would be low.

\section{Acknowledgement}

This study was supported by a grant obtained from the Swedish Agency for Research Co-operation in the developing countries (SAREC). 


\section{References}

1. BRODA, P. (1979) Plasmids. W. H. Freeman \& Company, Oxford.

2. COWAN, S. T. (1975) Manual for the identification of medical bacteria. Cambridge University Press., Great Britain.

3. ERICSSON, HANS, M., SHERRIS, J. C. (1971) Antibiotic sensitivity testing. Acta Patbol. Et. Microbiol. Scand. B. Suppl., 217 : 76.

4. FALKOW, S. (1975), Infectious Drug Resistance, Pion Ltd.

5. KRISHNARAJAH, V \& VINAYAGAMOORTHY, T. (1982) Bacterial flora and wound infections in a surgical unit of the General Hospital, Jaffna. Jaffna Medical Journal XVIII (1), 7-17.

6. NOLTE, A. W. (1973) Oral Microbiology. The C. V. Mosby Company, London.

7. STOKES, J. (1968) Clinical bacteriology. Ed. 3. Reprinted 1970. Edward Arnold Publishers Ltd. London.

8. VINAYAGAMOORTHY, T. (1981) Antibiotic resistance patterns of enteric bacteria from hospital patients, healthy adults and contaminated drinking water in a developing country (Sri Lanka). Jaffna Medical Journah XVI (1), 54-63.

9. VINAYAGAMOORTHY, T. Epidemiology of R-plasmids among enterobacteriaceae in a developing country (Sri Lanka). Ph. D. Thesis, Univ. of Jaffna, Univ. of Uppsala, Sweden. 